\title{
Study on Kinetics of Transformation in Medium Carbon Steel Bainite at Different Isothermal Temperatures
}

\author{
Wei Pei, Wei Liu, Yue Zhang, Rongjian Qie and Aimin Zhao * \\ Collaborative Innovation Center of Steel Technology, University of Science and Technology Beijing, \\ Beijing 100083, China; peiwei@xs.ustb.edu.cn (W.P.); b20160467@xs.ustb.edu.cn (W.L.); \\ b20180502@xs.ustb.edu.cn (Y.Z.); qierongjian@xs.ustb.edu.cn (R.Q.) \\ * Correspondence: zhaoaimin@ustb.edu.cn
}

Citation: Pei, W.; Liu, W.; Zhang, Y.; Qie, R.; Zhao, A. Study on Kinetics of Transformation in Medium Carbon Steel Bainite at Different Isothermal Temperatures. Materials 2021, 14, 2721. https://doi.org/10.3390/ma14112721

Academic Editor: Elena Pereloma

Received: 1 April 2021

Accepted: 6 May 2021

Published: 21 May 2021

Publisher's Note: MDPI stays neutral with regard to jurisdictional claims in published maps and institutional affiliations.

Copyright: (c) 2021 by the authors. Licensee MDPI, Basel, Switzerland. This article is an open access article distributed under the terms and conditions of the Creative Commons Attribution (CC BY) license (https:// creativecommons.org/licenses/by/ $4.0 /)$.

\begin{abstract}
Ultra-fine carbide-free bainitic (UCFB) steel, also known as nano-bainite (NB) steel, is composed of bainitic ferrite laths with nanoscale thickness and carbon-rich film-like retained austenite located between laths. The bainite transformation kinetic model can accurately describe the bainite transformation kinetics in conventional austempering (CA) processes based on the shear mechanism combined with the dilatometer test. UCFB steels with medium and high carbon composition are designed in this work to systematically study the transformation kinetics of bainite, and the evolution of its microstructure and properties, and reveal the influence of heat treatment processes on the microstructure and properties the UCFB steels. The results show that the activation energy for $\mathrm{BF}$ nucleation decreases during the CA process and isothermal transformation temperature decreases. The bainite transformation is first nucleated at the grain boundaries, and then nucleated at the newly formed bainitic ferrite/austenite interface.
\end{abstract}

Keywords: ultra-fine carbide-free bainitic steel; phase transition kinetics

\section{Introduction}

Bainitic phase transformation is an intermediate transition in the process of supercooled austenite transformation. After holding the austenitized steel at a temperature slightly above the martensitic transformation temperature for a period of time, Bhadeshia [1] obtained a steel with a metallographic organization of nano-sized slatted bainitic ferrite and interslatted carbon-rich austenitic films. This steel, with high carbon and silicon content, has been widely noted for its excellent mechanical properties after heat treatment. Lowcarbon bainitic steels that can be used to produce automotive parts have been researched extensively. The medium carbon bainitic steels have higher strength but less toughness than the low carbon bainitic steels. They can be used to produce wear-resistant parts for mines, railway rails, bearings and so on. Li [2] used bainitic steel, with a composition that ranged from $0.45 \%$ to $0.65 \% \mathrm{C}, 2.00 \%$ to $4.00 \% \mathrm{Mn}, 0.20 \%$ to $2.00 \% \mathrm{Si}$, to manufacture wear-resistant liners for mining machines that have more than double the service life under the same conditions than those made of Hadfield steel. With less hardness than martensitic steel, bainitic steel bearings show better wear resistance than martensitic steel bearings due to better toughness [3,4]. The increased toughness will further improve the wear resistance of the bearing [5].

The austenite that remains in the steel without transformation will have an important influence on the properties of the steel. The residual austenite in carbide-free bainite will yield first when receiving a load and then undergo a martensitic or bainitic phase transformation, which facilitates stress relief and can inhibit crack expansion under certain load conditions [6]. The volume and morphology of residual austenite in bainite can have a serious impact on the properties. Residual austenite with larger dimensions undergoes martensitic transformation in the early stages of the deformation process, while residual austenite distributed at grain boundaries with smaller size is more stable $[7,8]$. 
Bainitic transformation usually takes longer compared with martensitic transformation, and the time required for bainitic transformation of high-carbon steels is longer, even up to hundreds of hours [9]. By studying the kinetics of bainite phase transformation in Fe-2.98Cr-0.2Mn-0.38C (wt.\%) steel, Kelly et al. [10] found that the initial bainite phase transformation is rapid, but then the phase transformation gradually stops. A higher isothermal transformation temperature will result in a faster bainite transformation rate, but less austenite will be converted to bainite. Pre-deformation can provide conditions for bainite nucleation and shorten the gestation time for bainite formation [11,12], but it can also reduce the growth rate of bainite and slow down the overall transformation rate [13]. The martensite produced by pre-phase transformation can also provide an interface for bainite nucleation and accelerate the process of bainite transformation [14,15]. In this article, the UCFB steels with medium carbon composition were designed to study the transformation kinetics of bainite and the evolution of its microstructure.

\section{Materials and Methods}

The steel investigated was medium-carbon-rich silicon steel with the chemical composition: $0.50 \mathrm{C}-2.56 \mathrm{Si}-1.07 \mathrm{Mn}-2.30 \mathrm{Cr}-0.0016 \mathrm{Nb}-0.0052 \mathrm{~B}$ (wt.\%). The preparation technology and phase transformation temperatures (Ac1, Ac3, Ms) of investigated steel are described in literature [16,17]. Ac1 and Ac3 were measured as 774 and $864^{\circ} \mathrm{C}$ at a heating rate of $200{ }^{\circ} \mathrm{C}$ per h. Ms were measured as $187^{\circ} \mathrm{C}$ at a cooling rate of $20^{\circ} \mathrm{C}$ per s.

The conventional austempering experiments were conducted using DIL 805A, as shown in Figure 1. The conventional austempering consisted of austenitization at $950{ }^{\circ} \mathrm{C}$ for $10 \mathrm{~min}$, followed by cooling to 330,300 and $270{ }^{\circ} \mathrm{C}$, and the corresponding hold for 4,8 and $12 \mathrm{~h}$, hereinafter referred to as CA-330, CA-300 and CA-270.

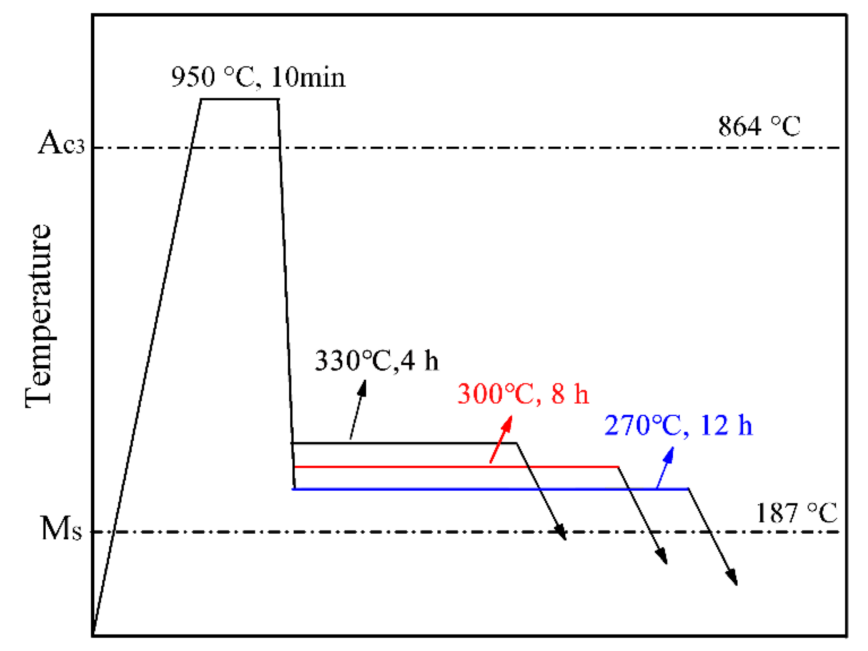

Time

Figure 1. Schematic diagram of heat treatments used to understand bainite formation kinetics.

The microstructure morphology and phase distribution were characterized with a ZEISS ULTRA 55-type field emission scanning electron microscope (SEM) operating at $20 \mathrm{kV}$. Metallographic samples for SEM were ground, mechanically polished and etched with 2 vol. \% nital. Transmission electron microscopy (TEM) was carried out on a Tecnai G2 F30 S-TWIN operated at $200 \mathrm{KV}$. The TEM samples were sliced into $300 \mu \mathrm{m}$ from cylindrical samples. These were ground down to $50 \mu \mathrm{m}$, and then followed by double-jet thinning in the electrolyte of $5 \%$ perchloric acid and $95 \%$ glacial acetic acid, as the voltage was $25 \mathrm{~V}$, the current was about $25 \mathrm{~mA}$, and the temperature was $30^{\circ} \mathrm{C}$.

The volume fraction of retained austenite (RA) was measured by $\mathrm{X}$-ray diffraction (XRD), operating at $40 \mathrm{KV}$ and a current of $150 \mathrm{~mA}$ with $\mathrm{Cu}-\mathrm{K} \alpha$ radiation. The $2 \theta$ scanning angles were varied from 45 to 95 with a stepping angle of $0.05^{\circ}$ and a counting time of $1.2 \mathrm{~s}$ per step using $10 \times 10 \mathrm{~mm}^{2}$ specimens. The volume fraction of retained austenite was 
calculated by measuring the integrated intensities of the (200), (220) and (311) austenite peaks, and comparing them with (200), (211) ferrite peaks [18].

\section{Results and Discussion}

\subsection{Subsection}

Figure 2 shows the dilation curves and dilatational rate curves of samples under the CA process. The straightness in the early stages and the end stages of the dilation curves indicates that the sample's bainite transformation is in the incubation period and the completion stage. Data on thermal expansion of CA-330 and CA-270 are described in the literature $[16,17]$. The incubation period time and complete transition time of bainite are 1364 and 19,080 s for CA-270. As the temperature increases, the time required for both incubation and complete transformation becomes shorter. The relevant transition times and transition rates are listed in the Table 1.
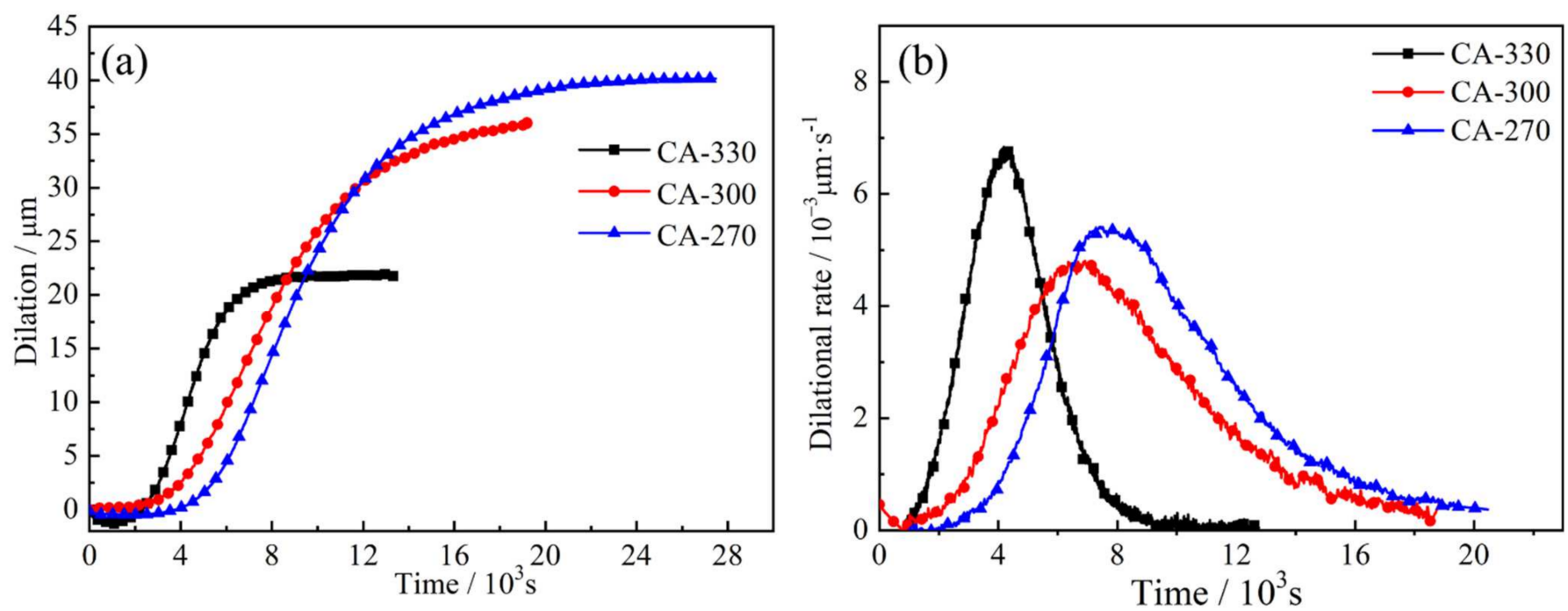

Figure 2. The dilation curves (a) and dilatational rate curves (b) of samples under CA process.

Table 1. Bainite phase transformation parameters at different isothermal temperatures.

\begin{tabular}{cccc}
\hline & CA-330 & CA-300 & CA-270 \\
\hline Incubation Period Time $/ \mathrm{s}$ & 804 & 1364 & 3000 \\
Complete Transition Time $/ \mathrm{s}$ & 10,962 & 19,080 & 26,980 \\
Maximum Transition Speed time $/ \mathrm{s}$ & 4217 & 6600 & 7603 \\
Maximum Transformation Rate $/ \mu \mathrm{m} \cdot \mathrm{s}^{-1}$ & 0.0067 & 0.0047 & 0.0054 \\
\hline
\end{tabular}

\subsection{Microstructure Characterizations}

The typical microstructures of specimens are composed of bainitic ferrite $(\mathrm{BF})$ and retained austenite (RA) under the CA process, as shown in Figure 3. According to the morphology of RA, it can be divided into the film retained austenite (FRA) and blocky retained austenite (BRA), as shown in Figure 3a-c. The TEM micrographs of the CA-270 sample are shown in Figure 3d. According to the formula [19], the BF thickness of CA-270 sample is $66 \pm 18 \mathrm{~nm}$. 

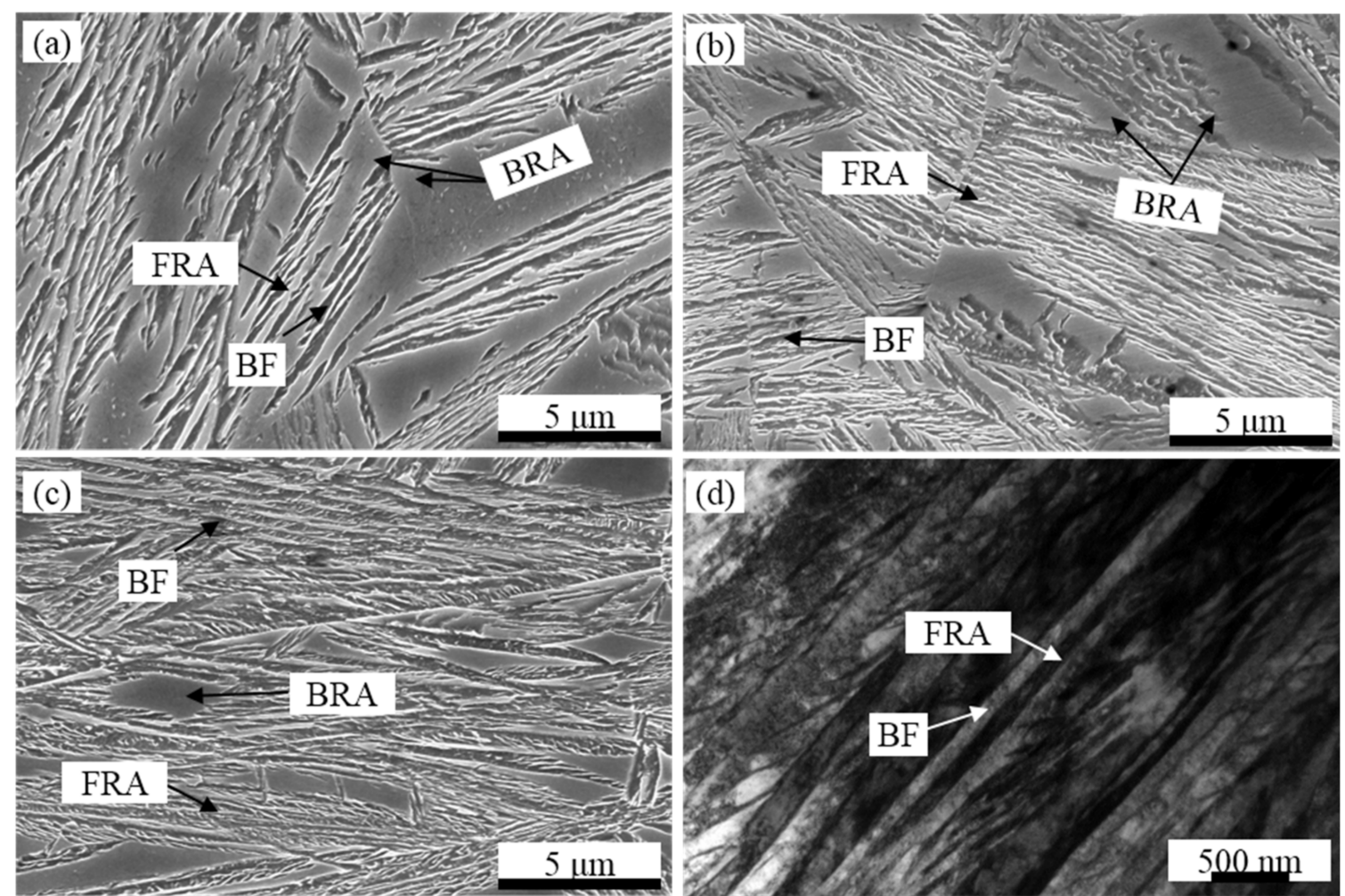

Figure 3. SEM (a-c) and TEM (d) microstructures of specimens austempered at various temperatures. FRA is film retained austenite; BRA is blocky retained austenite; BF is bainitic ferrite. (a) CA-330, (b) CA-300, (c,d) CA-270.

The XRD patterns of the experimental steel at different temperatures are shown in Figure 4. The structure comprises BCC (BF) and FCC (RA) at different temperatures, and no carbides are generated. The content of RA in CA-330, CA-300 and CA-270 samples is $32.5 \%, 28.6 \%$ and $24.8 \%$, respectively.

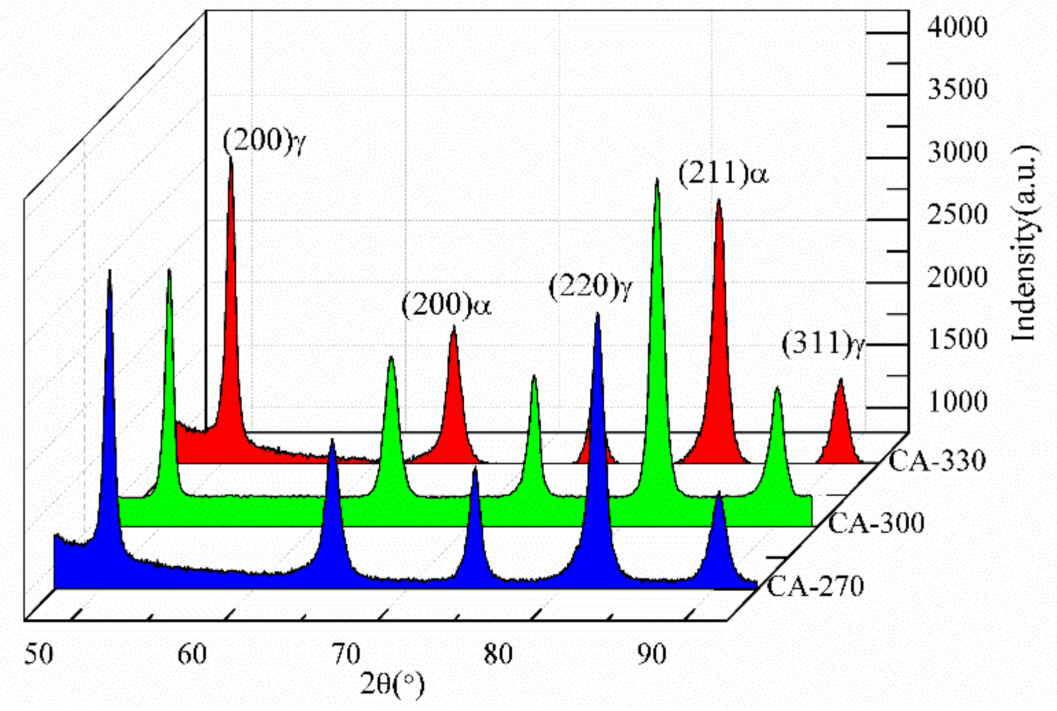

Figure 4. XRD patterns for samples isothermally treated at different temperatures. 


\subsection{Bainite Transformation Kinetics during CA Process}

\subsubsection{Fraction of Bainite Transformation}

Dilatometry data and XRD data can obtain the relationship between the volume fraction of bainite and isothermal holding time. The instantaneity volume fraction of bainite can be expressed by the following formula:

$$
f_{b}(t)=f_{b} \times \frac{L(t)-L_{0}}{L_{\infty}-L_{0}}
$$

where $f_{b}(t)$ and $f_{b}$ are the instantaneity bainite volume fraction and the final bainite volume fraction, respectively. $L(t), L_{0}$ and $L_{\infty}$ stand for the instantaneity length, initial length and final length of the dilatometry sample. The variation in bainite volume fraction and bainite transformation rate with isothermal holding time is shown in Figure 5a,b, respectively. The variation trend of bainite transformation and bainite transformation rate with isothermal temperature is similar to that of expansion quantity. Therefore, the variation trend of bainite transformation and bainite transformation rate with temperature is not described here.
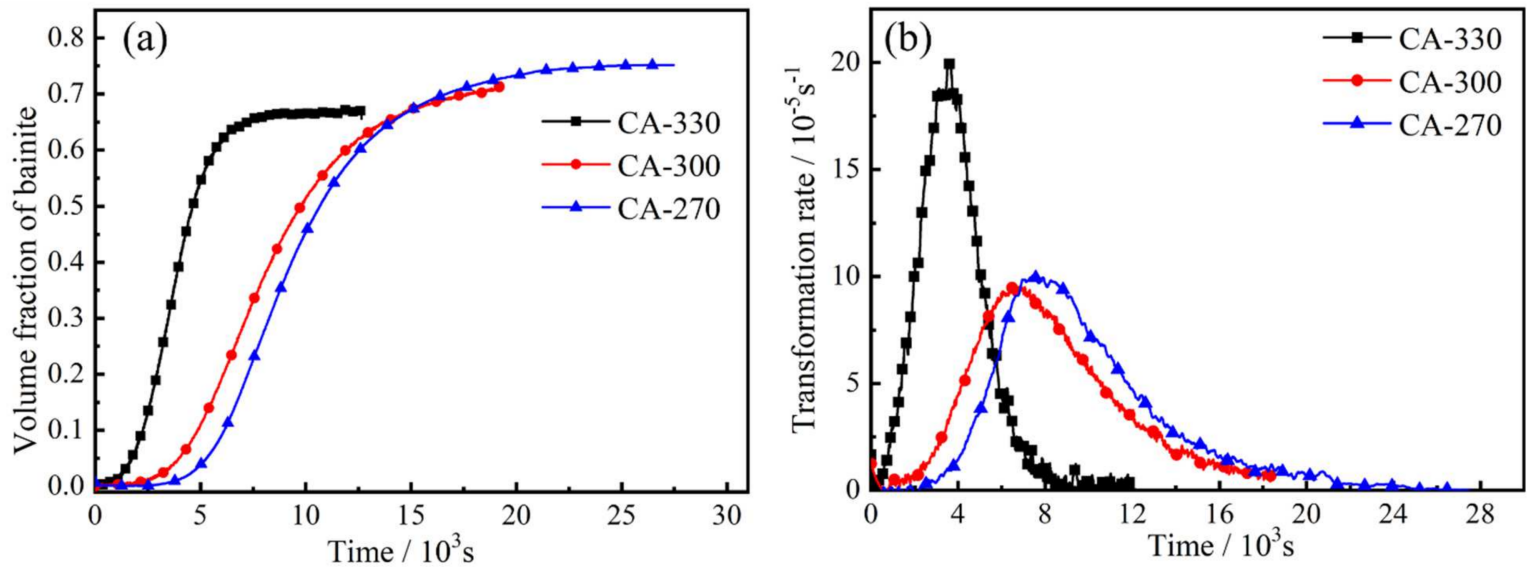

Figure 5. (a) Volume fraction of bainite, (b) transformation rate as a function of isothermal holding time at CA process.

\subsubsection{Modeling of Bainite Transformation}

In this work, the theoretical basis of predicting kinetics of bainite transformation in the CA process is the concept of the displacive theory of bainite transformation. According to the displacive theory of bainite transformation, bainite transformation occurs under the condition that both of the following conditions are met [20]:

$$
\begin{gathered}
\Delta \mathrm{G}_{\mathrm{m}}<\mathrm{G}_{\mathrm{N}} ; \text { where } \Delta \mathrm{G}_{\mathrm{m}}=\mathrm{G}_{\mathrm{m}}^{\alpha}-\mathrm{G}_{\mathrm{m}}^{\gamma} \\
\Delta \mathrm{G}^{\gamma \rightarrow \alpha}<-\mathrm{G}_{\mathrm{SB}} ; \text { where } \Delta \mathrm{G}^{\gamma \rightarrow \alpha}=\mathrm{G}^{\alpha}-\mathrm{G}^{\gamma}
\end{gathered}
$$

where $\Delta G_{m}$ is the maximum driving force for nucleation. $G_{m}^{\alpha}$ and $G_{m}^{\gamma}$ stand for the ferrite free energy and austenite free energy, respectively. $G_{N}$ is the universal nucleation function [20]. $\Delta \mathrm{G}^{\gamma \rightarrow \alpha}$ is the change in free energy in bainite transformation. $\mathrm{G}^{\alpha}$ and $\mathrm{G}^{\gamma}$ give the ferrite free energy and austenite free energy, respectively, when both the composition of ferrite and austenite is equal to the composition of interest. $\mathrm{G}_{\mathrm{SB}}$ is the stored energy of bainite, usually considered to be $400 \mathrm{~J} \mathrm{~mol}^{-1}$ [20]. The temperature at which $\Delta \mathrm{G}_{\mathrm{m}}=\mathrm{G}_{\mathrm{N}}$ and $\Delta \mathrm{G}^{\gamma \rightarrow \alpha}=-\mathrm{G}_{\mathrm{SB}}$ are called $T_{h}$ and $T_{0}^{\prime}$ temperature, respectively [21].

The bainite shear theory believes that bainite nucleates and grows at the interface. At the beginning of bainite transformation, bainite ferrite nucleates at prior austenite/austenite interface, that is, grain boundary nucleation. Once the bainite ferrite is formed, the bainite will nucleate at the tip of interface newly formed bainite/austenite; that is, autocatalytic nucleation. The microstructure of the experimental steel treated by the CA process is 
composed of bainitic ferrite and retained austenite, and the interfaces present in the tissue are the pristine austenite interface and the bainitic ferrite/ferrite interface. According to Bohemen and Sietsma's transformation model and the model improved by Ashwath, the overall bainite nucleation rate of the experimental steel under the CA process can therefore be expressed as the sum of the grain boundary nucleation rate and the autocatalytic nucleation rate.

The bainite shear theory states that bainite is nucleated and grows at the interface between different phases. The interfaces present in the specimens are the original austenite interface and the bainitic ferrite/ferritic interface. At the beginning of bainite transformation, bainitic ferrite is first nucleated at the pristine austenite interface (grain boundary nucleation). Once bainitic ferrite is generated, the bainitic ferrite nucleates at the tip of the freshly formed bainitic ferrite/austenite interface (autocatalytic nucleation). The overall bainite nucleation rate of this experimental steel under the CA process can be expressed as the sum of the grain boundary nucleation rate and the autocatalytic nucleation rate. The formula is expressed as:

$$
\begin{aligned}
\frac{d f}{d t}=\left(\frac{d f}{d t}\right)_{G}+\left(\frac{d f}{d t}\right)_{A} & =\frac{k T}{h} \frac{Z \delta}{d} m f_{\gamma}\left(T_{h}-T\right)\left[e^{\frac{-Q_{G}^{*}}{R T}}+f_{b} e^{\frac{-Q_{A}^{*}}{R T}}\right] \\
& =\frac{k T}{h} \frac{Z \delta}{d} m\left(T_{h}-T\right)(1-f) \frac{T_{0}^{\prime}-T}{T_{0 \bar{X}}^{T}-T}\left[1+f_{b} e^{\frac{\Delta Q^{*}}{R T}}\right]\left(e^{\frac{-Q_{G}^{*}}{R T}}\right)
\end{aligned}
$$

where: $(d f / d t)_{G}$ and $(d f / d t)_{A}$ are grain-boundary nucleation and autocatalytic nucleation, respectively; $k$ for Boltzmann constant, $1.38 \times 10^{-23} \mathrm{~J} \cdot \mathrm{K}^{-1} ; h$ for Planck constant, $6.626 \times 10^{-34} \mathrm{~J} \cdot \mathrm{s} ; \mathrm{Z}$ for geometrical factor, $6 ; \delta$ for the effective thickness of the austenite grain boundary, $1 \mathrm{~nm}$; $d$ for the prior austenite grain diameter; $m$ for the kinetics parameter giving an account of the relationship between martensite nucleation number and the degree of undercooling in $K^{-1} ; f_{r}$ for volume fraction of remaining available austenite; $f$ for volume fraction of bainite; $R$ for the molar gas constant, $8.314 \mathrm{~J} \cdot \mathrm{mol}^{-1} \cdot K^{-1} ; Q_{G}^{*}$ and $Q_{A}^{*}$ for the activation energy of bainite nucleation at grain boundary and autocatalytic nucleation, respectively; $\Delta Q^{*}$ for the difference in activation energy between grain boundary nucleation and autocatalytic nucleation; $T_{h}$ for the maximum temperature that the bainite nucleus can develop; $T_{0}^{\prime}$ for the highest temperature for which the diffusionless growth of bainite can take place; and the parameters $\left(T_{h}, T_{0}^{\prime}\right.$ and $\left.Q_{G}^{*}\right)$ vary linearly with an increase in carbon enrichment of austenite, and are described in the literature [22].

$$
\begin{gathered}
T_{h}=T_{h \bar{X}}-C_{1} \frac{f\left(\bar{X}-X_{b}\right)}{1-f} \\
T_{0}^{\prime}=T_{0 \bar{X}}^{\prime}-C_{2} \frac{f\left(\bar{X}-X_{b}\right)}{(1-f)} \\
Q_{G}^{*}=Q_{G \bar{X}}^{*}+K_{G} C_{1} \frac{f\left(\bar{X}-X_{b}\right)}{1-f}
\end{gathered}
$$

where: $T_{h \bar{X}}, T_{0 \bar{X}}^{\prime}$ and $Q_{G \bar{X}}^{*}$ are the $T_{h}$ temperature, $T_{0}^{\prime}$ temperature and activation energy for grain-boundary nucleation at start of the transformation; $C_{1}\left(C_{2}\right)$ is the constant between $T_{h}\left(T_{0}^{\prime}\right)$ and carbon content; and $X_{b}$ and $\bar{X}$ are the carbon content in bainite and bulk carbon content.

The values of various parameters in the model are shown in Table 2. The parameters of $T_{h \bar{X}}, T_{0}^{\prime} \overline{\mathrm{X}}^{\prime}, C_{1}$ and $C_{2}$ were calculated by a computer program, MUCG $83 . K_{\Gamma}$ and $\mathrm{m}$ are calculated by the empirical formula described in papers [23-25]. The grain size of prior autenite was simulated by JMatPro software. 
Table 2. The calculated values of various parameters in the model.

\begin{tabular}{ccccccc}
\hline$T_{\mathrm{h} \overline{\mathrm{X}}} / \boldsymbol{K}$ & $C_{\mathbf{1}} / \mathbf{K}$ & $\mathrm{T}_{\mathbf{0} \overline{\mathrm{X}}}^{\prime} / \mathbf{K}$ & $C_{\mathbf{2}} / \mathbf{K}$ & $\boldsymbol{K}_{\Gamma} / \mathrm{J} \cdot \mathbf{m o l}^{-\mathbf{1}} \cdot \boldsymbol{K}^{-\mathbf{1}}$ & $m / \mathbf{K}^{-\mathbf{1}}$ & $d / \mu \mathrm{m}$ \\
\hline 680.6 & 100.0 & 776.5 & 168.8 & 110.1 & 0.015 & 34 \\
\hline
\end{tabular}

The calculated curves have a very high fitting degree with the experimental curves, especially in the initial stage of bainite transformation, as shown in Figure 6. Figure 6a,c,e depicts the comparison between the fitted values and experimental values of bainite volume fraction as a function of isothermal holding time. In the initial stage of bainite transformation, the nucleation position of bainite is mainly prior austenite boundary. Therefore, the fitted value of $Q_{G \bar{X}}^{*}$ is very reliable. With bainite transformation, bainite gradually increased; grain-boundary nucleation and autocatalytic nucleation are the main types of bainite. The reasonable degree of this part is also very high. When the bainite transformation enters the later stage, due to the increase in bainite ferrite and the depletion of grain boundary nucleation position, the bainite transformation mainly takes the form of autocatalytic nucleation. The fitting results show that the reasonable degree of CA-300 and CA-270 is relatively high, indicating that the relevant result of autocatalytic activation energy is highly reliable. However, the reasonable degree of CA-330 is quite different in the later transformation stage, indicating that autocatalytic activation energy's relevant result has a large deviation. Figure $6 \mathrm{~b}, \mathrm{~d}, \mathrm{f}$ is a fitting comparison diagram of the transformation rate. It can be seen that the fitting results of the bainite transformation rate have the same trend as the experimental results. The fitting results in the latter part of the transformation rate fitting results show that the applicable rate is significantly slower than the experimental results, as shown in Figure 6b, which indicates that the autocatalytic activation energy is larger in the late stage of the process.

As shown in Figure 7a, the model's value of $Q_{G \bar{X}}^{*}$ and $\Delta Q^{*}$ at different austempering temperatures are fitted. The value of $Q_{A \bar{X}}^{*}$ at different isothermal temperatures is also calculated. The $Q_{G \bar{X}}^{*}$ and $Q_{A \bar{X}}^{*}$ show a linear decline trend with the austempering temperature. The results are the same as those reported in the literature [22,26], which indicates that the fitting results in this paper are credible. It should be noted that the activation energy is not divided into grain boundary activation energy and autocatalytic activation energy, except in the literature $[22,27]$. In Figure $7 \mathrm{a}$, the blue area between the black dotted line and the red dotted line represents the difference between the initial grain boundary activation energy and the autocatalytic activation energy, ranging from 30 to $32 \mathrm{~kJ} / \mathrm{mol}$. Figure $7 \mathrm{~b}$ describes bainite's activation energy of different experimental steels, which ranges from 11 to $180 \mathrm{~kJ} / \mathrm{mol}[22,27-35]$. The activation energy of bainite isothermal transformation is all within the range, which indicates that the fitting results are reliable.

The schematic diagram of bainite nucleation and growth under the CA process can be summarized, as shown in Figure 8. At the initial stage of bainite transformation (stage I), the bainite transformation amount is very small. The microstructure interfaces are mainly austenite/austenite interfaces, bainite nucleation at the grain boundary. The number of bainite ferrite/austenite interfaces increases with the increase in bainite content. Bainite can nucleate at the newly formed bainite ferrite/austenite interface. At this stage (stage II), bainite nucleates at the austenite/austenite interface and the ferrite/austenite interface. As the bainite transformation enters the later stage (stage III), the prior austenite grain boundary's nucleation position is exhausted, and the available volume fraction of austenite decreases, the nucleation rate of bainite decreases. It is mainly dominated by the bainite ferrite/austenite interface, namely autocatalysis nucleation. 

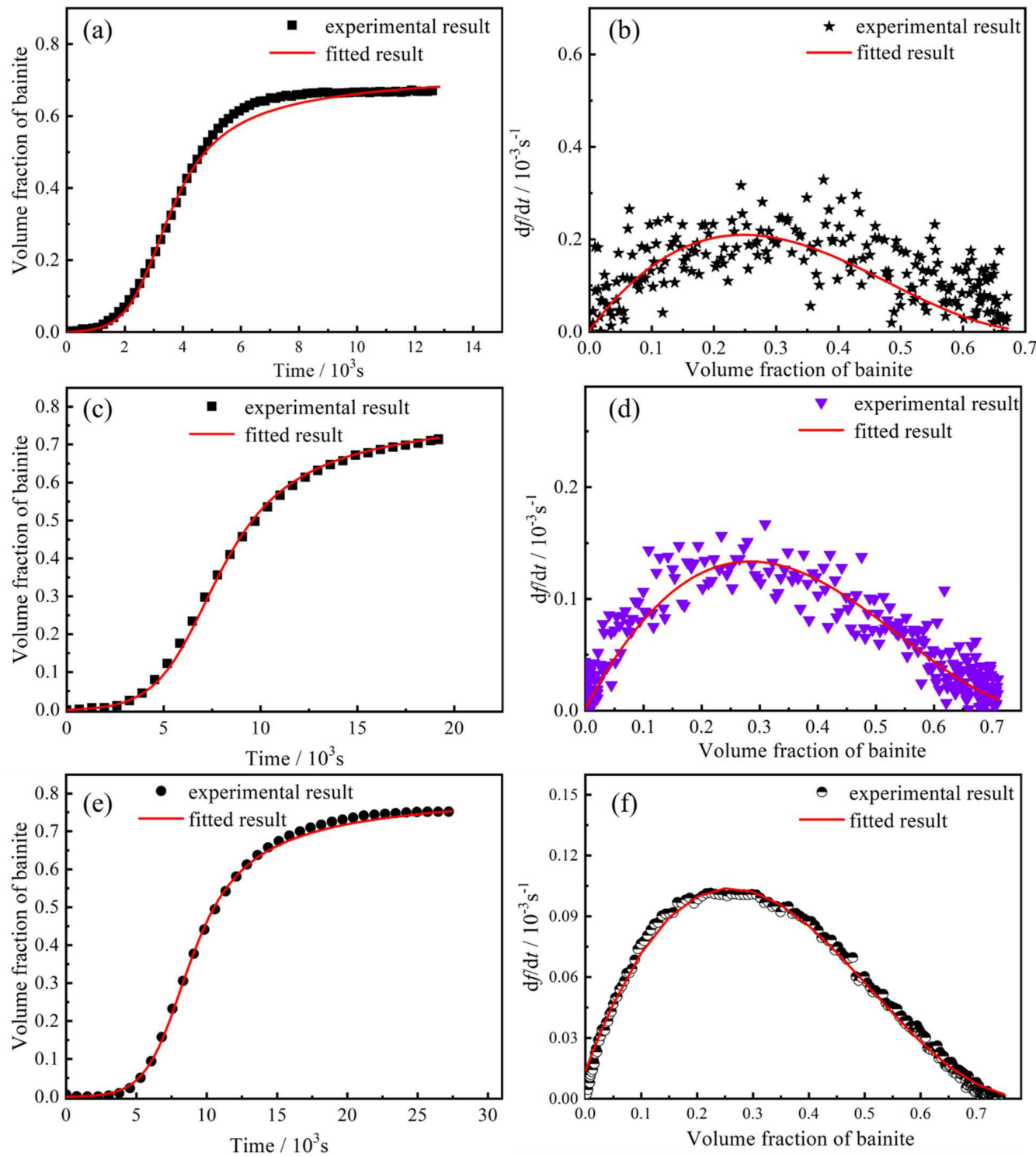

Figure 6. The calculated values and experimental values of CA-330 sample, CA-300 sample and CA-270 sample. (a,c,e) volume fraction of bainite as a function of isothermal holding time; $(\mathbf{b}, \mathbf{d}, \mathbf{f})$ transformation rate as a function of volume fraction of bainite.
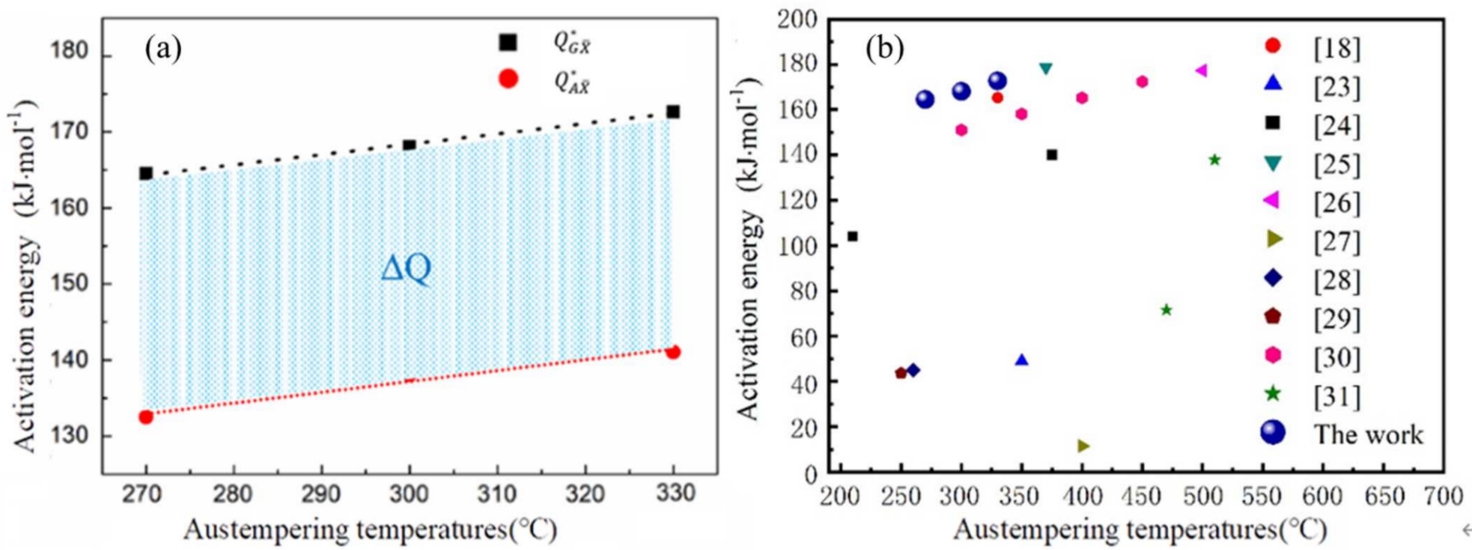

Figure 7. (a) The value of $Q_{G \bar{X}}^{*}$ and $Q_{A \bar{X}}^{*}$ as a function of undercooling; (b) activation energy in this paper value compared with other research results. 


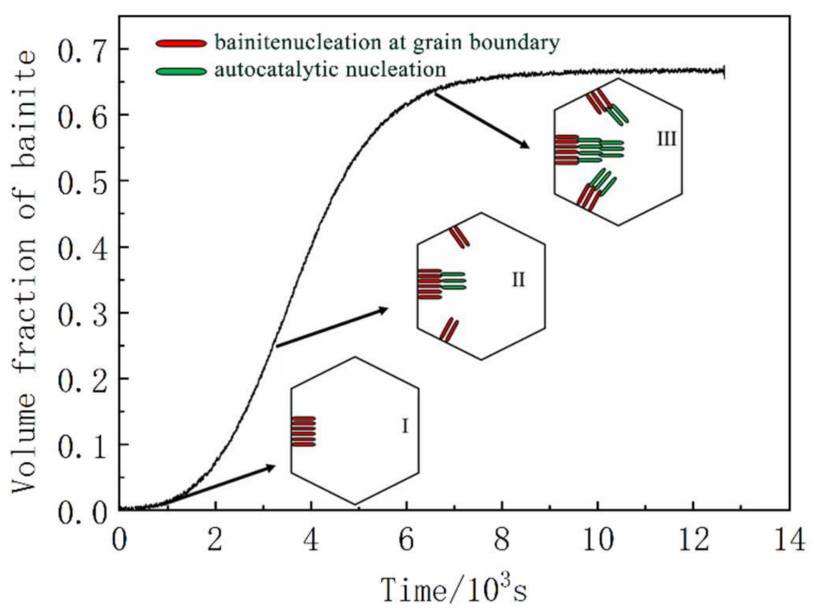

Figure 8. Schematic diagram of bainite nucleation under CA process.

\section{Conclusions}

Isothermal bainite transformation was carried out at different temperatures in this experiment. The results show that a higher content of residual austenite is obtained by isothermal transformation at higher temperatures, with lower carbon content in the residual austenite. The residual austenite content in the steel after isothermal phase transformation at 330,300 and $270{ }^{\circ} \mathrm{C}$ was $32.5 \%, 28.6 \%$ and $24.8 \%$, respectively. In addition to this, less time is required for the bainite transformation to reach its maximum transforming rate when the isothermal transformation is higher. In contrast, the bainite ferrite thickness, film residual austenite thickness, and body residual austenite size become smaller when the bainite transformation temperature is lower. In contrast, the bainite ferrite thickness, film residual austenite thickness and body residual austenite size become smaller when the bainite transformation temperature is lower. The activation energy for nucleation at the grain boundaries is higher than that for nucleation at the bainitic ferrite/austenite interface.

Author Contributions: Conceptualization, W.L., W.P. and A.Z.; methodology, W.L., W.P. and A.Z.; software, W.L. and A.Z.; validation, W.P. and Y.Z.; formal analysis, W.P. and A.Z.; investigation, R.Q.; resources, W.L. and A.Z.; data curation, W.P. and W.L.; writing-original draft preparation, W.P. and W.L.; writing-review and editing, W.P.; visualization, W.L. and Y.Z.; supervision, A.Z.; project administration, A.Z.; funding acquisition, A.Z. All authors have read and agreed to the published version of the manuscript.

Funding: This research was supported by the National Key Research and Development Plan of China (Grant No. 2016YFB0300205, No 2017YFB0304801) and the National Natural Science Foundation of China (NSFC: U1810207).

Institutional Review Board Statement: Not applicable.

Informed Consent Statement: Not applicable.

Data Availability Statement: This study did not report any data.

Conflicts of Interest: The authors declare no conflict of interest.

\section{References}

1. García Caballero, F.; Bhadeshia, H.K.D.H.; Mawella, K.J.A.; Jones, D.G.; Brown, P. Very Strong Low Temperature Bainite. Mater. Sci. Technol. 2002, 18, 279-284. [CrossRef]

2. Li, F.Z.; Ao, Q.; Jiang, J.; Li, Q.; Cao, L. Ultrafine Structure Bainitic Steels. Heat Treat. Met. 1998, 1, 7-9.

3. Wasiluk, K.; Skołek, E.; Swiatnicki, W. Microstructure and Properties of Surface Layer of Carburized 38CrAlMo6-10 Steel Subjected to Nanostructurization by a Heat Treatment Process/Struktura I Właściwości Warstwy Naweglanej Na Stali 38Cralmo6-10 Po Procesie Nanostrukturyzacji W Warunkach Obróbki Cieplnej. Arch. Metall. Mater. 2014, 59, 1685-1690. [CrossRef]

4. Zhang, P.; Zhang, F.C.; Yan, Z.G.; Wang, T.S.; Qian, L.H. Wear Property of Low-Temperature Bainite in the Surface Layer of a Carburized Low Carbon Steel. Wear 2011, 271, 697-704. [CrossRef] 
5. Ahmadi Miab, S.; Avishan, B.; Yazdani, S. Wear Resistance of Two Nanostructural Bainitic Steels with Different Amounts of Mn and Ni. Acta Metall. Sin. 2016, 29, 587-594. [CrossRef]

6. Yamashita, T.; Koga, N.; Umezawa, O. Mechanical Stability and Deformation-Induced Transformation of Retained Austenite in TRIP Steels at Low Temperatures. Key Eng. Mater. 2017, 741, 36-41. [CrossRef]

7. Akhbarizadeh, A.; Shafyei, A.; Golozar, M.A. Effects of Cryogenic Treatment on Wear Behavior of D6 Tool Steel. Mater. Des. 2009, 30, 3259-3264. [CrossRef]

8. Lee, Y.K.; Shin, H.C.; Jang, Y.C.; Kim, S.H.; Choi, C.S. Effect of Isothermal Transformation Temperature on Amount of Retained Austenite and Its Thermal Stability in a Bainitic Fe-3\%Si-0.45\%C-X Steel. Scr. Mater. 2002, 47, 805-809. [CrossRef]

9. Caballero, F.G.; Bhadeshia, H.K.D.H. Very Strong Bainite. Curr. Opin. Solid State Mater. Sci. 2004, 8, 251-257. [CrossRef]

10. Kelly, P.M.; Nutting, J.; Cottrell, A.H. The Martensite Transformation in Carbon Steels. Proc. R. Soc. Lond. Ser. A Math. Phys. Sci. 1961, 259, 45-58. [CrossRef]

11. He, J.; Zhao, A.; Zhi, C.; Fan, H. Acceleration of Nanobainite Transformation by Multi-Step Ausforming Process. Scr. Mater. 2015, 107, 71-74. [CrossRef]

12. He, B.; Xu, W.; Huang, M. Effect of Boron on Bainitic Transformation Kinetics after Ausforming in Low Carbon Steels. J. Mater. Sci. Technol. 2017, 33, 1494-1503. [CrossRef]

13. Bhadeshia, H.K.D.H. The Bainite Transformation: Unresolved Issues. Mater. Sci. Eng. A 1999, 273-275, 58-66. [CrossRef]

14. Toji, Y.; Matsuda, H.; Raabe, D. Effect of Si on the Acceleration of Bainite Transformation by Pre-Existing Martensite. Acta Mater. 2016, 116, 250-262. [CrossRef]

15. Avishan, B.; Tavakolian, M.; Yazdani, S. Two-Step Austempering of High Performance Steel with Nanoscale Microstructure. Mater. Sci. Eng. A 2017, 693, 178-185. [CrossRef]

16. Liu, W.; Zhang, B.; Zhao, A.; Guo, H.; Sun, S. Control of Morphology and Dimension of Blocky Retained Austenite in MediumCarbon Steel. Mater. Res. Express 2018, 6, 016526. [CrossRef]

17. Liu, W.; Liang, J.; Jiang, Y.; Zhang, B.; Zhao, A. A Study of Blocky Retained Austenite and Properties under Variously Heat-Treated Ultra-Fine Bainitic Steel. Mater. Res. Express 2019, 6, 105607. [CrossRef]

18. Kim, C. X-Ray Method of Measuring Retained Austenite in Heat Treated White Cast Irons. J. Heat Treat. 1979, 1, 43-51. [CrossRef]

19. Garcia-Mateo, C.; Caballero, F.G.; Bhadeshia, H.K.D.H. Acceleration of Low-Temperature Bainite. ISIJ Int. 2003, 43, 1821-1825. [CrossRef]

20. Bhadeshia, H.K.D.H. A Rationalisation of Shear Transformations in Steels. Acta Metall. 1981, 29, 1117-1130. [CrossRef]

21. Bhadeshia, H.K.D.H. Bainite in Steels; Woodhead Pub Ltd.: Cambridge, UK, 2001.

22. Ravi, A.M.; Sietsma, J.; Santofimia, M.J. Exploring Bainite Formation Kinetics Distinguishing Grain-Boundary and Autocatalytic Nucleation in High and Low-Si Steels. Acta Mater. 2016, 105, 155-164. [CrossRef]

23. Van Bohemen, S. Modeling Start Curves of Bainite Formation. Metall. Mater. Trans. A 2009, 41, 285. [CrossRef]

24. Van Bohemen, S.M.C.; Sietsma, J. Effect of Composition on Kinetics of Athermal Martensite Formation in Plain Carbon Steels. Mater. Sci. Technol. 2009, 25, 1009-1012. [CrossRef]

25. HajyAkbary, F.; Sietsma, J.; Miyamoto, G.; Furuhara, T.; Santofimia, M.J. Interaction of Carbon Partitioning, Carbide Precipitation and Bainite Formation during the Q\&P Process in a Low C Steel. Acta Mater. 2016, 104, 72-83. [CrossRef]

26. Van Bohemen, S.M.C.; Sietsma, J. Modeling of Isothermal Bainite Formation Based on the Nucleation Kinetics. Int. J. Mater. Res. 2008, 99, 739-747. [CrossRef]

27. Ravi, A.M.; Navarro-López, A.; Sietsma, J.; Santofimia, M.J. Influence of Martensite/Austenite Interfaces on Bainite Formation in Low-Alloy Steels below Ms. Acta Mater. 2020, 188, 394-405. [CrossRef]

28. Van Bohemen, S.M.C.; Sietsma, J. The Kinetics of Bainite and Martensite Formation in Steels during Cooling. Mater. Sci. Eng. A 2010, 527, 6672-6676. [CrossRef]

29. Samanta, S.; Biswas, P.; Giri, S.; Singh, S.B.; Kundu, S. Formation of Bainite below the MS Temperature: Kinetics and Crystallography. Acta Mater. 2016, 105, 390-403. [CrossRef]

30. Ravi, A.M.; Sietsma, J.; Santofimia, M.J. Bainite Formation Kinetics in Steels and the Dynamic Nature of the Autocatalytic Nucleation Process. Scr. Mater. 2017, 140, 82-86. [CrossRef]

31. Han, X.; Zhang, Z.; Rong, Y.; Thrush, S.J.; Barber, G.C.; Yang, H.; Qiu, F. Bainite Kinetic Transformation of Austempered AISI 6150 Steel. J. Mater. Res. Technol. 2020, 9, 1357-1364. [CrossRef]

32. Luzginova, N.V.; Zhao, L.; Sietsma, J. Bainite Formation Kinetics in High Carbon Alloyed Steel. Mater. Sci. Eng. A 2008, 481-482, 766-769. [CrossRef]

33. Song, C. Investigation of Competitive Mechanism during Partitioning and Deformation Coordination Mechanism of I\&QP Steel. Ph.D. Thesis, University of Science and Technology Beijing, Beijing, China, 2019.

34. Lan, L. Bainite Transformation Characteristics and Fracture Micomechanism of Q690cf Steels under the Welding Thermal Cycle. Ph.D. Thesis, Northeastern University, Boston, MA, USA, 2013.

35. Van Bohemen, S.M.C.; Santofimia, M.J.; Sietsma, J. Experimental Evidence for Bainite Formation below Ms in Fe-0.66C. Scr. Mater. 2008, 58, 488-491. [CrossRef] 